\title{
Pronunciation of Turkish
}

Since 1928 , Turkish words are written with a version of the Latin alphabet. The letter $c$ is pronounced as the hard $j$ in $j a z z ; c$ (c cedilla) as the $c b$ in $c h a i r$; 1 (undotted $i$ ) as the $u$ in run or er in water; $i$ as the $i$ in rich; ss (s cedilla) as the $s h$ in ship; $\ddot{o}$ (o umlaut) as the $e u$ in the French peu; $\ddot{u}$ (u umlaut) as the $u$ in the French $t u$; and the $\breve{g}$ (soft $\mathrm{g}$ ) either lengthens the sound of the preceding vowel or takes on the sound of a soft $y$ when it appears before front vowels. 
